\title{
ASO Author Reflections: Uptake of Surgical Innovations: More Evidence and Less Opinion and Enthusiasm
}

\author{
Marko Simunovic, MD (D), and Pablo Serrano, MD \\ Department of Surgery, Faculty of Health Sciences, McMaster University, Hamilton, Canada
}

How does a surgical innovation get taken up in large geographic regions? A previous study demonstrated that only perceptions of "comparative advantage" influenced uptake by surgeons of intraoperative demonstrations of total mesorectal excision techniques. ${ }^{1}$ Chassin suggested that marked differences in surgical procedure rates among large geographic regions was driven by relative surgeon enthusiasm. ${ }^{2}$ Opinion leaders may have an outsized influence on practice patterns among peers. We concurrently evaluated the potential role of comparative advantage, enthusiasm, and opinion leaders on the uptake of laparoscopic resection for colorectal cancer liver metastases.

We found that, in Ontario (population 13.5 million), uptake of this complex and expensive innovation was haphazard, not driven by comparative advantage, and appeared mostly influenced by relative enthusiasm among opinion leader surgeons. ${ }^{3}$ Deming paraphrased that "every system is perfectly designed to get the result that it does." 4 The Ontario healthcare ecosystem, like parallel systems around the world, is a complex interplay of stakeholder actions occurring in economic, political, and social realities. In the absence of high-quality evidence, in the Ontario "system," the most pertinent stakeholders driving the uptake of many surgical innovations are likely surgeon enthusiasts and instrument companies.

Regarding laparoscopic resection of liver metastases in Ontario, some patients in low-rate regions are not receiving an important treatment advance, or in high-rate regions,

\section{(C) Society of Surgical Oncology 2020}

First Received: 23 September 2020

Accepted: 25 September 2020;

Published Online: 20 October 2020

M. Simunovic, MD

e-mail: simunovi@hhsc.ca resources are being diverted to an ineffective therapy. This dichotomy can only be conflated through the production of high-quality evidence, with an important caveat. Enthusiasts lead most surgical innovation trials, and there is a lack of blinding, raising the risk of observer bias (e.g., patient trial arm unconsciously influences treatment decisions). Ideally, surgical innovations should be evaluated using expertisebased randomized trials, where patients are randomized to surgeons expert in the procedure of interest versus the current standard of care. ${ }^{5}$ The rarity of such trials demonstrates how far we must collectively travel to place patient needs at the center of our health ecosystems - though this is the future.

DISCLOSURES The authors declare no conflicts of interest.

\section{REFERENCES}

1. Simunovic M, Coates A, Smith A, Thabane L, Goldsmith $\mathrm{CH}$, Levine MN. Uptake of an innovation in surgery: observations from the cluster-randomized Quality Initiative in Rectal Cancer trial. Can J Surg. 2013;56(6):415-421. https://doi.org/10.1503/cjs. 019112

2. Chassin MR. Explaining geographic variations: The enthusiasm hypothesis. Med Care. 1993; 31(5): 37-44.

3. Wang J, Serrano P, Griffiths G, Parpia S, Simunovic M. Enthusiasm, opinion leaders, comparative advantage and the uptake of laparoscopic resection for colorectal cancer liver metastases in Ontario, Canada: a population-based cohort study. Ann Surg Oncol. 2020. h ttps://doi.org/10.1245/s10434-020-09203-0.

4. Deming. "Every System Is Perfectly Designed to Get the Results It Gets." The W. Edwards Deming Institute, deming.org/quotes/ $10141 /$.

5. Waltho D., Davidge K., Eskicioglu C., for the Evidence-Based Surgery Working (2019) Expertise-Based Randomized Controlled Trials. In: Thoma A., Sprague S., Voineskos S., Goldsmith C. (eds) Evidence-Based Surgery. Springer, Cham. https://doi.org/10.1007/ 978-3-030-05120-4_14

Publisher's Note Springer Nature remains neutral with regard to jurisdictional claims in published maps and institutional affiliations. 